\title{
Conformational, Fluorescence and Energy Parameters of Interferon $\alpha 2 b$ with Different Forms of Oligoribonucleotides and Adenosine Monophosphate ${ }^{\dagger}$
}

\author{
Roman Nikolaiev *, Yevhenii Stepanenko, Svitlana Chernykh, Natalia Melnichuk and Zenovii Tkachuk
}

Citation: Nikolaiev, R.; Stepanenko, Y.; Chernykh, S.; Melnichuk, N.; Tkachuk, Z. Conformational, Fluorescence and Energy Parameters of Interferon $\alpha 2 \mathrm{~b}$ with Different Forms of Oligoribonucleotides and Adenosine Monophosphate. Proceedings 2020, 78, 16. https:// doi.org/10.3390/IECP2020-08697

Published: 1 December 2020

Publisher's Note: MDPI stays neutral with regard to jurisdictional claims in published maps and institutional affiliations.

Copyright: $\odot 2020$ by the authors. Licensee MDPI, Basel, Switzerland. This article is an open access article distributed under the terms and conditions of the Creative Commons Attribution (CC BY) license (http://creativecommons.org/licenses/by/4.0/).
Institute of Molecular Biology and Genetics of NASU, 03143 Kyiv, Ukraine; stepanenkojack@gmail.com (Y.S.); chernykhimbg@gmail.com (S.C.); natalia.melnichuk8@gmail.com (N.M.); ztkachuck47@gmail.com (Z.T.)

* Correspondence: romanfromukrain@gmail.com

+ Presented at the 1st International Electronic Conference on Pharmaceutics, 1-15 December 2020; Available online: https://iecp2020.sciforum.net/.

\begin{abstract}
Background: It is known that RNA in $\mathrm{Na}^{+}$salt form has only immunomodulatory activity, and in acid form additionally acquires anti-inflammatory activity and in combination with D-mannitol acquires an even broader antiviral effect. The study aimed to study the ability of adenosinmonophosphat (AMP) and oligoribonucleotides (ORNs) in acid and salt form and in combination with D-mannitol to affect the conformation and fluorescence of interferon (INF) $\alpha-2 \mathrm{~b}$ and to determine the energy parameters of these interactions. (2) Methods: spectroscopy (time pulsed and fluorescence), isothermal nanocalorimetry. (3) Results: AMP and ORNs in acid form and complex with D-mannitol bind more strongly to interferon $\alpha-2 b$ than salt analogues. In the interaction of interferon $\alpha-2 \mathrm{~b}$ and acid AMP and especially in complex with D-mannitol, the reaction occurs exothermically and change in conformational mobility INF by increasing the content of disordered regions. When INF $\alpha-2 b$ interacts with salt AMP, the reaction occurs endothermically, and probably the salt form increases the conformational stiffness of INF $\alpha-2 b$. The greater efficiency of nonradiative energy transfer from INF $\alpha-2 b$ to acid AMP has been shown, due to the closer distance between molecules. (4) Conclusions: AMP in acid form interacts more actively and increases the conformational mobility of INF, at a greater relative distance and with less Gibbs energy compared to the salt form, which probably causes the appearance of additional biological properties of acidic AMP.
\end{abstract}

Keywords: oligonucleotides; interferon $\alpha 2 \mathrm{~b}$; lifetime of fluorescence; isothermal titration calorimetry

\section{Introduction}

Drugs based on oligoribonucleotides from yeast RNA have a reasonably low solubility in the range of $0.5-3 \mathrm{mg} / \mathrm{mL}$. Our previous studies have shown that oligoribonucleotides (ORNs) has anti-inflammatory properties, and ORNs with D-mannitol has anti-inflammatory and antiviral properties. The mechanism of this phenomenon is unclear. Dmannitol itself does not have these activities, but increases the solubility by 1.5-2 times and stabilizes the structure of the ORNs, which probably leads to new biological effects. In the course of our research, we found that D-mannitol affects the binding of ORNs to interferon and the thermodynamic and conformational parameters of this interaction [1-4].

Interactions of protein nucleic acids play a decisive role in many biological processes. RNA-based drugs that can bind and affect the work of epigenetic regulators and transcriptional proteins through interaction, with regulatory domains, can be used as safe analogs. In a previous work, we showed that the combination of oligonucleotides with alcohol sugar D-mannitol leads to changes in their biological activity and efficiency. ORNs increases interferon production and stimulate non-specific antivirus protection, but the molecular mechanism of its action is still unclear. Interactions of protein and nucleic acids 
play a decisive role in many biological processes. RNA-based drugs that can bind and affect the work of epigenetic regulators and transcriptional proteins through interaction, with regulatory domains, can be used as safe analogues. We studied the ability of yeast RNA (ORNs), yeast RNANa salt (ORNs $\mathrm{Na}$ ), and yeast ORNs:D-mannitol complex (ORNs:D-M) and AMP to effect on fluorescence quenching and conformational changes of interferon $\alpha 2 \mathrm{~b}$. To determine the energy parameters of protein-ligand interactions, we use isothermal titration nanocalorimetry Nano ITC.

\section{Experiments}

The integrity and molecular weight of interferon $\alpha-2 \mathrm{~b}$ established by electrophoresis, and it was equal to about $18.2 \mathrm{kDa}$ (Figure 1).

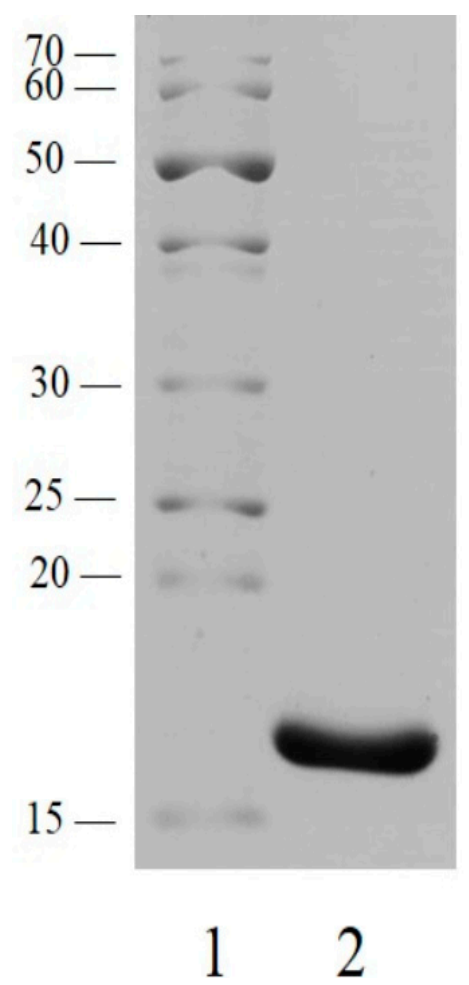

Figure 1. Gel electrophoresis of interferon $\alpha-2 b$ : 1-a mixture of marker proteins "PageRuler Unstained Protein Ladder"; 2 -interferon $\alpha-2 \mathrm{~b} \sim 18.2$ kDa.

We analyzed the molecular weight and purity of interferon $\alpha-2 b$ from gel electrophoresis. We used $10 \%$ polyacrylamide gel under denaturing conditions with addition SDS by Lemley method [5]. Standard solution of a mixture of marker proteins with a known molecular weight "PageRuler Unstained Protein Ladder" manufactured by "Thermo Fischer Scientific" (Waltham, MA, USA) and $10 \mu \mathrm{L}$ of the test solution (protein) at a concentration of $50 \mu \mathrm{g} / \mu \mathrm{L}$ was applied to the appropriate cells and added to the next well.

Materials Interpharmbiotek Kyiv, Ukraine, kindly provided the recombinant interferon $\alpha$-2b. D-mannitol was obtained from Sigma Aldrich, St. Louis, MO, USA, and the total acid yeast RNA preparation was provided by SC "BioCell", Kyiv, Ukraine. The work was performed on the acid form and RNA complex with D-mannitol in a weight ratio of 2.5:1, as well as on the sodium salt of total yeast RNANa and the salt RNA complex with D-mannitol. The ratio of 2.5 to 1 was chosen as a result of previous experiments conducted in our laboratory with MCR-ALS analysis of mixtures of RNA with sugars, as it was found that it is at this ratio of components that a complex is formed [6].

The method of fluorescence spectroscopy used to study the interaction of different forms of RNA with interferon $\alpha-2 b$. Fluorescence spectra were recorded in the range of $300-450 \mathrm{~nm}$ on a spectrofluorimeter Jasco FP-8200 at room temperature using a cuvette 1 
$\mathrm{cm}$ To measure the spectra of interferon $\alpha-2 \mathrm{~b}$ (IFN $\alpha-2 \mathrm{~b}$ ) was dissolved in $50 \mathrm{~mm}$ Tris- $\mathrm{HCl}$ buffer $(\mathrm{pH}-7,5)$ at a temperature $\mathrm{t}=25^{\circ} \mathrm{C}$; scanning speed $-200 \mathrm{~nm} / \mathrm{min}$; excitation slit width $=2.5 \mathrm{~nm}$; radiation slit width $=2.5 \mathrm{~nm}$; the final protein concentration was $1 \mu \mathrm{m}$; and the final concentration of titrants $\approx 10 \mu \mathrm{m}$ [7]. We performed the experiment in $50 \mathrm{mM}$ Tris- $\mathrm{HCl}$ buffer ( $\mathrm{pH} 7.5)$ (RNA in the buffer does not convert to tris salt and remains stable because $\mathrm{HCl}$ is a more vital acid). The spectra of interferon $\alpha-2 \mathrm{~b}$ in the titration of RNA and RNA:D-mannitol complex were normalized. In this study, we calculated the protein binding constant of the ligands by nonparametric regression (Equations (1) and (2)) of the dependence of tryptophan autofluorescence of the protein on the concentration of the ligand.

$$
\begin{gathered}
m=1+\left(\frac{P}{D o}\right)+\left(\frac{K_{d}}{D_{0}}\right), \\
A=A_{f}-\left(A_{f}-A_{b}\right) *\left(0.5 m-\sqrt{0.25 m^{2}-\frac{P}{D_{0}}}\right)
\end{gathered}
$$

where $D_{0}$ is the concentration titrated substance, $P$ is the fluorescence value. $A_{f}$ is the maximum fluorescence, and $A_{b}$ is the minimum fluorescence. The spectra of interferon $\alpha-2 \mathrm{~b}$ and RNA and its RNA:D-mannitol complex were normalized.

The energy parameters of the ligand-protein interaction was determined by isothermal titrating nanocalorimetry. The number of injections was 25, and the interval between injections was $300 \mathrm{~s}$. The protein was pre-dialyzed against the buffer. There was a buffer in the comparison cell. We performed isothermal titration nanocalorimetry according to the method presented in [8] in $50 \mathrm{~mm}$ Tris- $\mathrm{HCl}$ buffer ( $\mathrm{pH}$ 7.5). By measuring the changes in heat release or absorption during the binding process, we calculated the thermodynamic parameters of the interaction reaction (enthalpy changes, Gibbs free energy, and entropy).

The efficiency of the energy interaction of Foster ligands with protein (Horiba FluoroMax 4 Plus fluorometer, Irvin, CA, USA) was determined by time division pulse spectroscopy. The experiment parameters were: scanning range-100 ns; number of channels - 4000; radiation gap $-2.5 \mathrm{~nm}$; excitation wave $-295 \mathrm{~nm}$; emission detection wave$337 \mathrm{~nm}$; the length of the optical track was $1 \mathrm{~cm}$. Lifetime defined as the exponential regression of the number of emission signals from the time: $I(t)=\exp (-t / \tau)$. Energy transfer efficiency is the ratio of the number of energy transfer events to the number of donor excitation events: $\mathrm{E}=1-\left(\tau \mathrm{D}^{\prime} / \tau \mathrm{D}\right)$, where $\tau \mathrm{D}^{\prime}$ and $\tau \mathrm{D}$ are the lifetime of the fluorescence donor in the presence and absence of the acceptor, respectively.

The effect of different forms of RNA on the secondary structure of the protein was determined by CD spectroscopy on a CD spectrometer JASCO J-815. Scanning range 260$195 \mathrm{~nm}$; number of passes-2; accumulation-2s; scanning speed-100 nm / min. Next, the $\mathrm{CD}$ spectrum in units of [mdeg] was converted in units of molecular ellipticity, taking into account the protein concentration and the optical path length of the cuvette $1 \mathrm{~cm}$. The spectra analyzed in the service http://bestsel.elte.hu. Among the components of the secondary structure, we calculated the content of $\alpha$-helices, which are divided into regularmiddle parts and relaxed - the ends of the helices; parallel and antiparallel beta-sheets, which are divided into three subgroups: left-handed, relaxed (with a rotation angle of up to $4^{\circ}$ to the left and right) and right-turned, as well as unstructured areas [7, 9-11].

\section{Results}

Interactions of protein and nucleic acids play a decisive role in many biological processes. RNA-based drugs that can bind and affect the work of epigenetic regulators and transcriptional proteins through interaction, with regulatory domains, can be used as safe analogs. We studied the ability of yeast RNA (ORNs), yeast RNANa salt (ORNs Na), and 
yeast ORNs:D-mannitol complex (ORNs:D-M) and AMP to effect on fluorescence quenching and conformational changes of Interferon $\alpha 2 \mathrm{~b}$. To determine the energy parameters of protein-ligand interactions, we used isothermal titration nanocalorimetry Nano ITC.

It is shown that when using ORNs and ORNs:D-M, quenching of the fluorescent INF was $18 \%$ and $21 \%$, while for AMP and AMP:DM, it was $12 \%$ and $16 \%$. Quenching of INF fluorescence in the titration of ORNssNa and ORNssNa:DM was $16 \%$ and $17 \%$, while for AMPNa and AMPNa:DM, it was $8 \%$ and $10 \%$ (Figure 2).
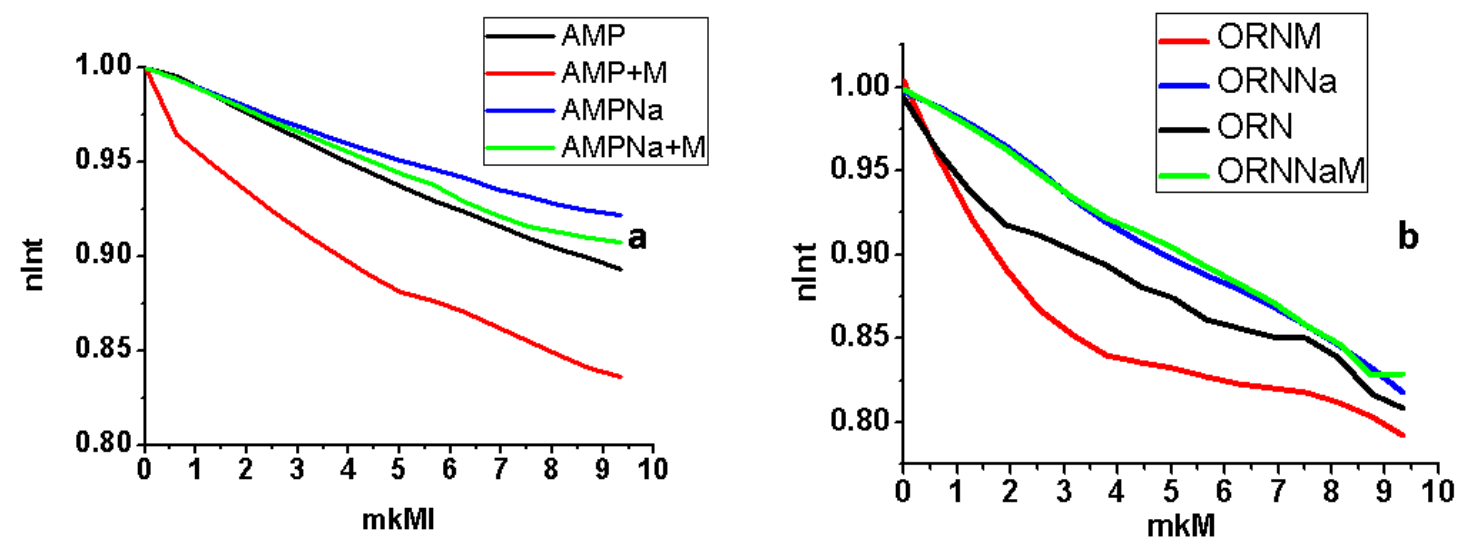

Figure 2. Dependence of quenching of interferon (IFN) emission intensity $\alpha$-2b $\lambda$ em $=336 \mathrm{~nm}$ with light-excited Xe lamps $\lambda \mathrm{ex}=295 \mathrm{~nm}$ on the concentration of (a) adenosinmonophosphat (AMP) and (b) oligoribonucleotides (ORNs) ligands and their complexes with D-mannitol.

The dissociation constant (Figure 3) is $\mathrm{Kd}=1.11 \pm 0.09 \mu \mathrm{M}$ in the fluorescence quenching interaction between INF and ORNs-D-M. The dissociation constant between IFN and ORNs is $\mathrm{Kd}=2.36 \pm 0.47 \mu \mathrm{M}$, between INF and ORNsNa it is $\mathrm{Kd}=9.15 \pm 0.16$ $\mu \mathrm{M}$, and between INF and ORNsNa-D-M it is $\mathrm{Kd}=8.13 \pm 0.46 \mu \mathrm{M}$. The dissociation constant is $\mathrm{Kd}=0.94 \pm 0.09 \mu \mathrm{M}$ in the fluorescence quenching interaction between INF and AMP-D-M. The dissociation constant between IFN and AMP is $\mathrm{Kd}=1.53 \pm 0.41 \mu \mathrm{M}$, between INF and AMPNa it is $\mathrm{Kd}=7.1 \pm 0.19 \mu \mathrm{M}$ and between INF and AMPNa-D-M it is $\mathrm{Kd}=8.14 \pm 0.73 \mu \mathrm{M}$.

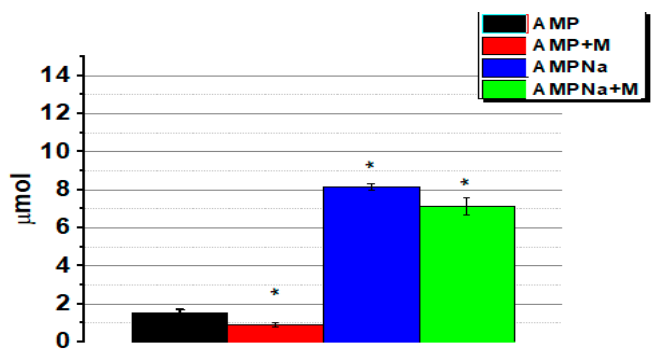

(a)

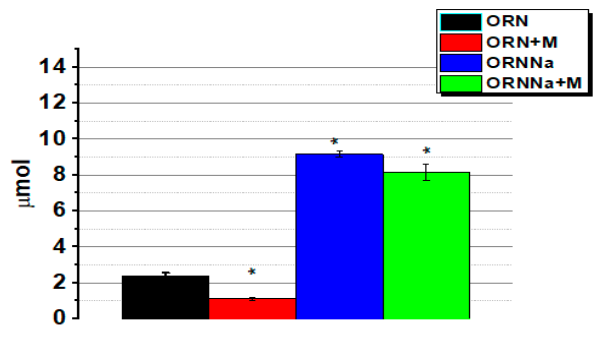

(b)

Figure 3. The binding constant of interferon $\alpha-2 b$ to (a) AMP and (b) oligonucleotides. $\mu \mathrm{mol}-1 \times$ $10^{-6}$ mol. *-statistically significant difference compared with the control INF, $p \leq 0.05$.

INF has a lifetime of $2.95 \mathrm{~ns}$ (Figure 4). When interacting with ORNs and ORNs:D$\mathrm{M}$, INF has a fluorescence time of 2.37 and $2.32 \mathrm{~ns}$, respectively, and when interacting with AMP and AMP: D-M, its fluorescence time is 2.01 and $1.92 \mathrm{~ns}$. When interacting with ORNsNa and ORNsNa:D-M, INF has a fluorescence time of 2.73 and 2.49 ns, respectively, and when interacting with AMPNa and AMPNa: D-M, it has a fluorescence time of 2.31 and $2.43 \mathrm{~ns}$. 


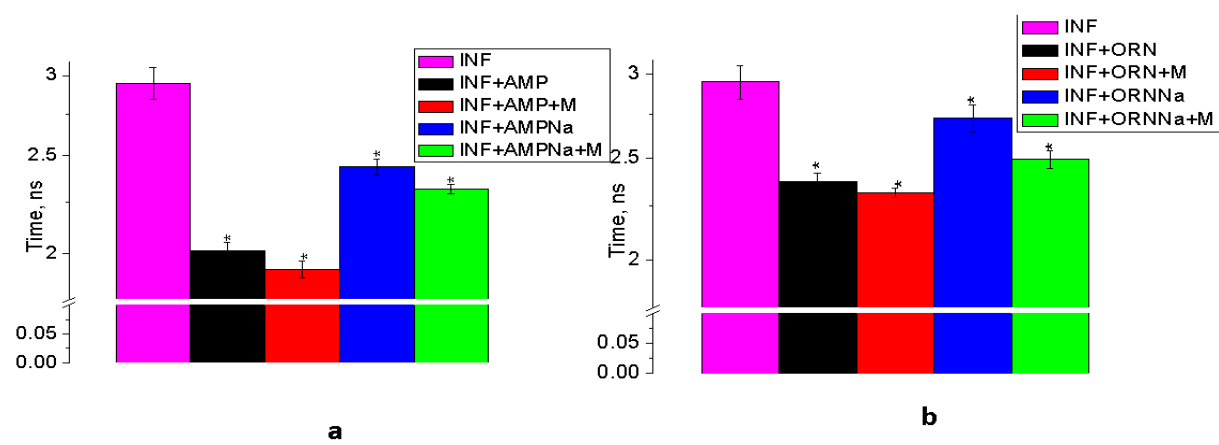

Figure 4. The fluorescence lifetime of interferon $\alpha-2 b$ with (a) AMP and (b) ORNs. * - statistically significant difference compared with the control INF, $p \leq 0.05$.

The enthalpy changes in the titration of interferon $\alpha-2 b$ acid form of ORNs and ORNs:D-M were -63.28 and $-96.61 \mathrm{~kJ} / \mathrm{mol}$, respectively, and for ORNsNa and ORNsNa:D-M, respectively, they were 4.52 and $5.14 \mathrm{~kJ} / \mathrm{mol}$ (Figure 5). The change in entropy when adding the ORNs to interferon $\alpha-2 \mathrm{~b}$ was -38.72 , and in the case of ORNs:D$\mathrm{M}$, it was $-63.53 \mathrm{~kJ} / \mathrm{mol}^{*} \mathrm{~K}$, respectively. The change in entropy when adding ORNsNa to interferon $\alpha-2 \mathrm{~b}$ was $17.05 \mathrm{~kJ} / \mathrm{mol}^{*} \mathrm{~K}$, and for the ORNsNa:D-M, respectively, it was 17.58 $\mathrm{kJ} / \mathrm{mol}^{*} \mathrm{~K}$. A similar pattern was demonstrated when studying the change in Gibb's energy during titration of interferon $\alpha-2 \mathrm{~b}$ with ORNs and ORNs:D-M, and it was -24.56 and $-33.07 \mathrm{~kJ} / \mathrm{mol}$, respectively. Additionally, when titrated with ORNsNa and its ORNsNa:D$\mathrm{M}$, respectively, it was -12.9 and $-12.43 \mathrm{~kJ} / \mathrm{mol}$.

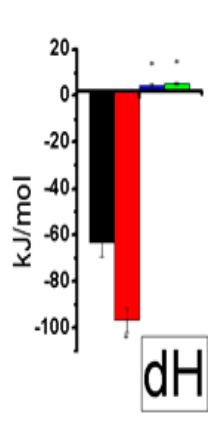

(a)

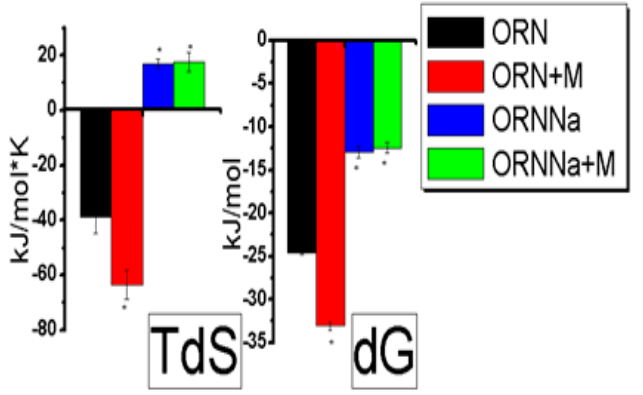

(b)

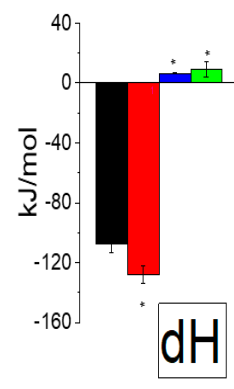

(d)

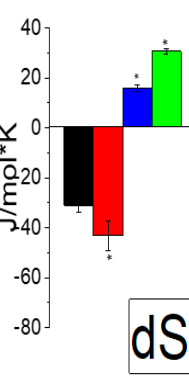

(e)

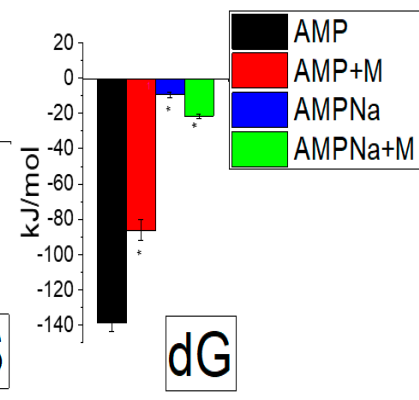

(f)

Figure 5. Changes in energy parameters during the interaction of interferon $\alpha-2 b$ with oligoribonucleotides. It is shown that positive energy indicators accompany the reaction of the interaction between interferon and acidic forms of RNA and their complex with D-mannitol, and with salt forms of ORNs and AMP and their complexes with D-mannitol-opposing arrows. The addition of D-mannitol to ORNs and AMP in both cases enhances the action of these ligands. (a,d) enthalpy; (b,e) entropy; (c,f) Gibb's energy. ${ }^{*}$-statistically significant difference compared with the control INF, $p \leq 0.05$.

The enthalpy changes in the titration of interferon $\alpha-2 b$ acid form of AMP and AMP:D-M were - 107.52 and $-127.91 \mathrm{~kJ} / \mathrm{mol}$, respectively, and for AMPNa and AMPNa:D$\mathrm{M}$, respectively, they were 6.46 and $9.16 \mathrm{~kJ} / \mathrm{mol}$ (Figure 5d). The change in entropy when adding the ORNs to interferon $\alpha-2 \mathrm{~b}$ was -31.12 , and in the case of AMP:D-M, it was -43.31 $\mathrm{kJ} / \mathrm{mol}^{*} \mathrm{~K}$, respectively. The change in entropy when adding AMP Na to interferon $\alpha-2 \mathrm{~b}$ was $15.9 \mathrm{~kJ} / \mathrm{mol}^{*} \mathrm{~K}$, and for the AMPNa:D-M, respectively, it was $30.71 \mathrm{~kJ} / \mathrm{mol}^{*} \mathrm{~K}$ (Figure 5e). A similar pattern was demonstrated when studying the change in Gibb's energy during titration of interferon $\alpha-2 \mathrm{~b}$ with ORNs and AMP:D-M, and it was -138.64 and -86.4 $\mathrm{kJ} / \mathrm{mol}$, respectively. Additionally, when titrated with AMPNa and its AMPNa:D-M, respectively, it was -9.4 and $-21.55 \mathrm{~kJ} / \mathrm{mol}$ (Figure $5 f$ ). 
These results (Figure 6) of studying the effects of thermodynamics of different forms of RNA and their complexes with D-mannitol in the titration of interferon $\alpha-2 \mathrm{~b}$ may indicate different sites of binding of different forms of ORNs to protein, as well as other modes of binding and various types of conformational changes in the protein.
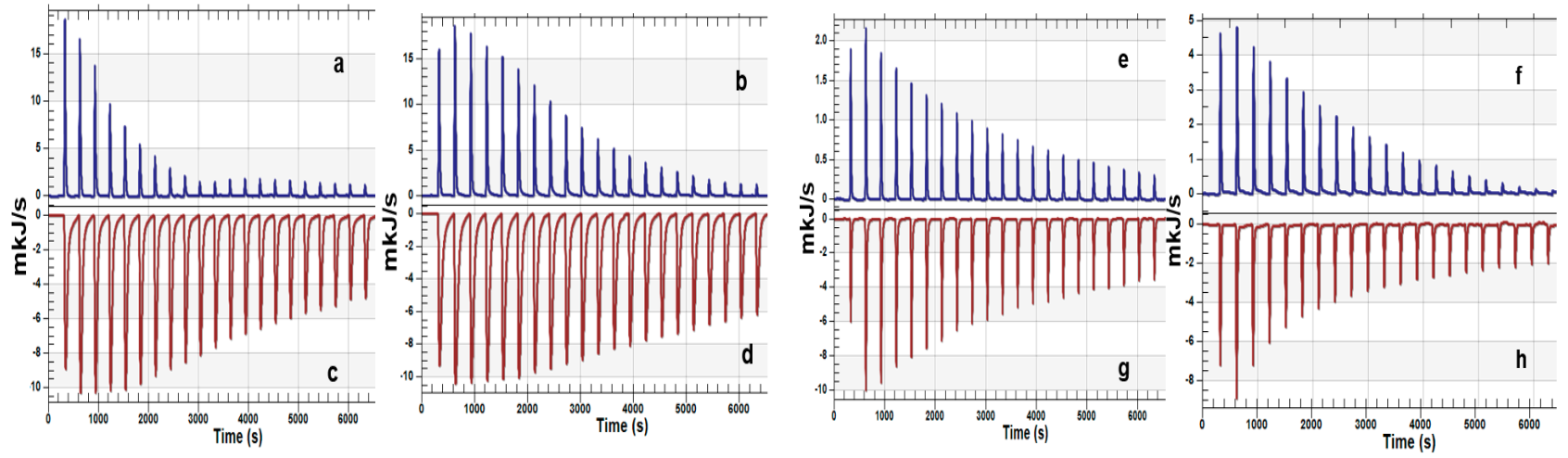

Figure 6. Curves of titration of different forms of ORNs and their D-mannitol complexes with interferon $\alpha-2 \mathrm{~b}$. (a) titration with acidic ORNs; (b) titration with a complex of the acidic form of ORNs and D-mannitol; (c) titration of ORNs Na; (d) titration of ORNs Na complex with D-mannitol; (e) titration with acidic AMP; (f) titration with a complex of the acidic form of AMP and D-mannitol; (g) titration of AMP Na; (h) titration of AMP Na complex with D-mannitol.

Thus, ORNs, especially ORNs:D-M and AMP:D-M, leads to a change in the conformational mobility of interferon $\alpha-2 \mathrm{~b}$ by increasing the content of disordered regions (Table 1 ). At the same time, salt analogues increase the number of structured secondary elements, such as $\alpha$-helices, $\beta$ turns, and $\beta$ antiparallel sheets, and probably increase the conformational stiffness of interferon $\alpha-2 b$.

Table 1. Changes in the secondary structure of interferon $\alpha-2 \mathrm{~b}$ during ORNs titration.

\begin{tabular}{|c|c|c|c|c|c|c|c|c|c|}
\hline $\begin{array}{l}\text { Secondary Ele- } \\
\text { ments of the } \\
\text { Structure }\end{array}$ & INF & $\begin{array}{l}\text { INF+ } \\
\text { ORNs }\end{array}$ & $\begin{array}{c}\text { INF+ } \\
\text { ORNs +M }\end{array}$ & $\begin{array}{c}\text { INF+ } \\
\text { ORNsNa }\end{array}$ & $\begin{array}{c}\text { INF+ } \\
\text { ORNsNa+ } \\
\text { M } \\
\end{array}$ & $\begin{array}{l}\text { INF+ } \\
\text { AMP }\end{array}$ & $\begin{array}{c}\text { INF+ } \\
\text { AMP +M }\end{array}$ & $\begin{array}{c}\text { INF+ } \\
\text { AMPNa }\end{array}$ & $\begin{array}{c}\text { INF+ } \\
\text { AMPNa+M }\end{array}$ \\
\hline$\alpha$-helixes regular & 26.6 & 17 & 15.8 & 31.8 & 32.3 & 16 & 19.8 & 30.6 & 35.3 \\
\hline $\begin{array}{c}\alpha \text {-helixes diffuse } \\
\text { antiparallel } \beta\end{array}$ & 11 & 10.8 & 10.4 & 12 & 15.2 & 9.4 & 9.3 & 11.3 & 14.2 \\
\hline $\begin{array}{l}\text { sheets right- } \\
\text { handed }\end{array}$ & 0 & 0 & 0.5 & 2.8 & 3 & 0 & 0.6 & 2.3 & 2.7 \\
\hline $\begin{array}{l}\text { antiparallel } \beta \\
\text { sheets relaxed }\end{array}$ & 8.1 & 8.8 & 7.1 & 9.1 & 11.3 & 8 & 7.1 & 9.0 & 11.1 \\
\hline $\begin{array}{c}\text { antiparallel } \beta \\
\text { sheets left-turn }\end{array}$ & 12.2 & 0 & 0 & 13.8 & 10.2 & 0.1 & 0 & 13.8 & 10.2 \\
\hline parallel $\beta$ sheets & 0 & 0 & 0 & 2 & 1 & 0 & 0 & 1.5 & 1 \\
\hline$\beta$ turns & 6.8 & 7.6 & 7.2 & 11.9 & 10.8 & 7.3 & 7.6 & 12.3 & 11.7 \\
\hline $\begin{array}{c}\text { unoganized } \\
\text { structure }\end{array}$ & 35.3 & 55.8 & 59 & 16.6 & 16.2 & 59.2 & 59 & 19.2 & 13.8 \\
\hline
\end{tabular}

\section{Discussion}

The obtained titration curves of interferon $\alpha-2 b$ from AMP indicate that the reaction of the interaction between protein and acid ligands occurs exothermically, and with salt it occurs endothermically. These results can be explained by the ability of AMP to bind multiple times to different binding sites on a molecule of a given protein. It is known from the literature that during protein-ligand interaction, the exothermic reaction is accompanied by an increase in protein activity, and the endothermic reaction is accompanied by inhibition [9]. Thus, in our case, the same AMP compound, depending on the form, can affect the conformation of the protein in different ways. When interferon $\alpha-2 b$ interacts with the 
acidic conditions of RNA, heat is released, and protons are exchanged from the acid form to the protein. When it interacts with salt forms, heat is absorbed, and are protons transferred from the protein to the AMP. Thus, by reducing the free binding energy between the acidic condition of AMP and its complex with D-mannitol by optimizing the enthalpic contribution, and this can significantly improve the pharmacological properties of interferon $\alpha-2 b$. However, this fact can suggest that the use of other preparations of RNA and DNA in acid form and especially in combination with D-mannitol can optimize their affinity for interaction with target proteins and thus discover new and improve known pharmacological properties.

However, we determined the values of the binding constants of various forms of RNA and their complexes with D-mannitol in micromolar amounts, which indicates lowaffinity interactions. Analysis of the literature shows that low-affinity interactions are much more widespread than previously thought. The results of recent studies have found that low-affinity interactions occur in large numbers between biologically significant molecules, including between macromolecules [12].

We have previously shown that in addition to the direct binding of RNA to the main active sites of the enzyme, another mechanism is possible by which ligands interact with proteins, in this case, oligoadenylates with protein kinases. This interaction can occur outside the functionally active sites of the protein kinase due to a change in the conformation of the protein, which, in turn, leads to a change in the activity of the enzyme. At the same time, under the action of oligoadenylates, not only inhibition but also increase of enzyme activity occurs [13].

The release or absorption of heat by the interaction of various forms of yeast RNA and its complexes with D-mannitol may indicate a change in the secondary structure of interferon $\alpha-2 b$. To confirm the assumption of a change in the conformation of this protein, we studied the secondary structure of interferon $\alpha-2 b$ under the action of various forms of RNA by circular dichroism. It is shown that RNA in acid form, and especially in complex with D-mannitol, leads to a change in conformational mobility due to an increase in the content of disordered regions. At the same time, salt analogues of RNA increase the number of structured secondary elements and possibly increase the conformational stiffness of interferon $\alpha-2 b$.

The most active quenching and decreased lifetime of fluorescence INF, when titrated with AMPs and ORNs, was obtained using acid forms in combination with mannitol. Additionally, when titrated, INF saline forms slightly different from the control. Spectra of circular dichroism show that the decrease in the structure of the number of secondary elements in the interaction between INF and acidic ligands forms nucleotides. An increase in the content of secondary structure in the interaction between INF and salt forms ligands. The ITC titration curves indicate that the reaction between protein and acidic ligands is exothermic. Additionally, the reaction between INF and saline ligands is endothermic. Exothermic protein-ligand interaction increases the conformational mobility of the protein and endothermic decrease.

The ORNs have the advantage of interacting with proteins, unlike salt ORNs and AMPs, because they have a stronger binding. Thus, we assume that the same compound in various forms may act as an inhibitor and activator for the protein.

The available literature suggests that there is probably no single general mechanism that could explain the different modes of binding of other forms of RNA observed experimentally. Most likely, disordered proteins combine functions such as pre-formed structure and flexibility, depending on the individual system and functional context [14]. From the results of our experiments, we can assume that different forms of RNA can bind to proteins, give relatively disordered fragments of the protein globule specific conformational stability by the indirect, spatially-mediated effect on functionally essential parts of the protein molecule. 


\section{Conclusions}

- $\quad$ AMP and ORNs in acidic form and combination with mannitol bind more strongly to interferon $\alpha-2 \mathrm{~b}$ than to saline analogs;

- In the interaction of interferon and AMP and ORNs in acidic form, the reaction is exothermic. The ITC curve is endothermic between interferon and ORNs and AMP in salt form;

- $\quad \mathrm{AMP}$ and acidic ORNs, and especially in combination with mannitol, lead to a change in conformational mobility by increasing the content of disordered sites. At the same time, salt analogs increase the number of structured secondary elements and probably increase the conformational rigidity of interferon;

- Pulse-time spectroscopy shows a higher efficiency of non-radiative energy transfer from interferon to AMP and ORNs in acidic form, due to the closer distance between molecules and the higher Foster transfer rate.

Institutional Review Board Statement: Not applicable.

Informed Consent Statement: Not applicable.

Data Availability Statement: The study did not report data so it can be excluded.

\section{References}

1. Sullenger, B.A.; Gilboa, E. Emerging clinical applications of RNA. Nature 2002, 418, 252-258.

2. Zemskov, A.M.; Zemskova, V.M.; Berezhnova, T.A.; Dyadina, K.S.; Kulintsova, Y.V.; Larin, A.V.; Korunyak, D.I. Immunosenetic diseases. Sci. Med. Bull. Cent. Chernozem Reg. 2018, 71, 97-102.

3. Kulkarni, A.D.; van Buren, C.T.; Rudolph, F.B. Ribonucleotide Preparations and Uses Thereof. U.S. Patent No. 5,712,256, 27 January 1988.

4. Tkachuk, Z. Compound, Composition and Method for the Treatment of Inflammatory and Inflammatory-Related Disorders. Patent PCT/US01/09590, 24 March 2000.

5. Laemmli, U.K. Cleavage of structural proteins during the assembly of the head of bacteriophage T4. Nature 1970, 227, 680-685, doi:10.1038/227680a0.

6. Vivcharyk, M.M.; Ilchenko, O.O.; Levchenko, S.M.; Tkachuk, Z.Y. Complexation of RNA with mannitol, its spectral characteristics and biological activity. Rep. Natl. Acad. Sci. Ukr. 2016, 10, 78-83, doi:10.15407/dopovidi2016.10.078.

7. Lakowicz, J.R. Principles of Fluorescence Spectroscopy, 3rd ed.; Springer: New York, NY, USA, 2006; 954p.

8. Loosli, F.; Vitorazi, L.; Berret, J.-F.; Stoll, S. Isothermal titration calorimetry as a powerful tool to quantify and better understand agglomeration mechanisms during interaction processes between $\mathrm{TiO}_{2}$ nanoparticles and humic acids. Environ. Sci. Nano 2015, 2, 541-550, doi:10.1039/c5en00139k.

9. Du, X.; Li, Y.; Xia, Y.-L.; Ai, S.-M.; Liang, J.; Sang, P.; Ji, X.-L.; Liu, S.-Q. Insights into Protein-Ligand Interactions: Mechanisms, Models, and Methods. Int. J. Mol. Sci. 2016, 17, 144, doi:10.3390/ijms17020144.

10. Loosli, F.; Vitorazi, L.; Berret, J.-F.; Stoll, S. Isothermal titration calorimetry as a powerful tool to quantify and better understand agglomeration mechanisms during interaction processes between $\mathrm{TiO}_{2}$ nanoparticles and humic acids. Environ. Sci. Nano 2015, 2, 541-550. doi:10.1039/c5en00139k.

11. Balasubramanian, V.; Nguen, L.T.; Balasubramanian, S.V.; Ramanathan, M. Interferon-y-Inhibitory Oligodeoxynucleotides Alter the Conformation of Interferon-y. Mol. Pharm. 1998, 53, 926-932.

12. Mollica, L.; Bessa, L.M.; Hanoulle, X.; Jensen, M.R.; Blackledge, M.; Schneider, R. Binding Mechanisms of Intrinsically Disordered Proteins: Theory, Simulation, and Experiment. Front. Mol. Biosci. 2016, 3, 52. doi:10.3389/fmolb.2016.00052.

13. Skorobogatov, O.Y.; Kukharenko, A.P.; Kozlov, O.V.; Dubey, I.Y.; Tkachuk, Z.Y. 2'-5'-Linked Triadenylates Actas Protein Kinase Activity Modulators. J. Proteom. Bioinform. 2017, 10, 320-323.

14. Ohtaka, H. Thermodynamic rules for the design of high affinity HIV-1 protease inhibitors with adaptability to mutations and high selectivity towards unwanted targets. Int. J. Biochem. Cell Biol. 2004, 36, 1787-1799. doi:10.1016/j.biocel.2004.02.021. 